\title{
APPLICATION OF SIMILARITY TRANSFORMATIONS IN GEODETIC MONITORING NETWORKS
}

\author{
Hisham Abou Halima * \\ Abo El Hassan F. Rahil ** \\ *Assistant Professor, faculty of Engineering, Mansoura University, Egypt. \\ **Associate Professor, faculty of Engineering, Shebin El-Kom, Minufiya University, Egypt.
}

\begin{abstract}
Similarity transformation are useful in the detection of deformation and for the connexion of geodetic networks. The estimated netpoints coordinates and their covariance matrix can be transformated from one computational base to another without repeating the adjustment process via an similarity transformation. The derivation of the transformation matrices is closely connected with the properties of generalised matrix inverses which have been mentioned in connection with inner constriants.

The main objective of this paper is to introduce the partial trace minimization approach as an proposed general solution technique for free geodetic net work. In addition the problem of transforming regular covariance matrix into a singular one with the required rank deficiency and vice verse will be solved. The structure of the transformation matrices for different datum defects have been deduced. Finally the use of similarity transformation to transform a covariance matrix from one computational base to another is introduced and disussed.Two numerical examples representing simulated and real geodetic networks were given in order to illustrate the application and the efficiency of the underlying theoretical concept.
\end{abstract}

KEYWORDS: Similarity transformation, Computational base, Innere constraints ;Transformation matrix , Partial trace minimization ,Datum - points. 
S - transformation are useful in the detection of deformation and for the connexion of geodetic networks. The coordinates of netpoints are estimated at different epochs. In order to compare the coordinates of positions of different epochs, their coordinate systems have to coincide and they have to be referred to the same datum. Different datum definitions between the epochs would lead to wrong conclusions, because the estimated coordinates being compared and their covariance matrix are datum dependant. The analysis and adjustment of each individual epoch is done in the form of a free network adjustment referring the datum to all coordinates of the epoch. The covariance matrix shows minimum trace with respect to all points coordinates $[1,4]$. Because of different intial coordinates, the datum of epochs to be compared might be different. This is also true if partial networks that were chosen to define the datum in the network adjustment are not identical between the epochs. In order to construct a common datum using partial trace minimization approach, either the individual epochs might be readjusted selecting a common set of points to define the datum, or an S - transformation of the result of the adjustment of each epoch could be performed The main objective of this paper is to introduce the partial trace minimization approach as an proposed general solution technique for free geodetic networks. In addition the problem of transforming regular covariance matrix into a singular one with the required rank deficiency and vice verse will be solved. Finally the use of $S$ - transformation to transform a covariance matrix from one computational base to another is introduced and discussed.

\section{MATHEMATICAL MODEL FOR ADJUSTMENT TECHNIQUES}

The mathematical model for the least squares adjustment by the method of observation equations is composed of the functional model, which is given in linear form by

$$
\mathbf{v}=\mathbf{A} \mathbf{x}-\mathbf{L}
$$

And the stochastic model

$$
P=Q_{1}^{-1}=\sigma_{0}^{2} C_{1}^{-1}
$$

Where $\mathrm{v}$ is the $\mathrm{nx} 1$ vector of residuals, $A$ is the nxu coefficient matrix, ( which is also commonly known as the configuration matrix or design matrix ), $\mathrm{x}$ is the uxl vector of unknown corrections to the approximate coordinates; $L$ is the nxl vector of the absolute terms; $P$ is the nxn weight matrix of the observations; $Q_{I}$ is the nxn weight coefficient matrix of the observations, $C_{1}$ is the nxn covariance matrix of the observations, and $\sigma_{0}^{2}$ is the a prior variance factor. The least squares solution of an overdetermind set of observation equations is obtained by setting [ 2,9$]$

$$
v^{r} P v=\text { minimum }
$$

The application of this criterion leads to the following system of normal equations 


$$
\left(A^{T} \mathbf{P A}\right) \cdot x=A^{T} \mathbf{P L}
$$

- In most engineering networks a datum defect, which equal to rank deficiency of the design matrix $\mathrm{A}$, will exist and the least squares estimate of parameters cannot be obtained since the normal equations coefficient matrix $\mathrm{N}$ will be singular. The reason for the rank deficiency is that the coordinate datum is not completely defined by the observations. In order to avoid this singularity in the normal equation coefficient matrix, two different approaches will be used.

\subsection{Classical Constrained Approach}

Classical constrained adjustment can be achieved by including external constraints on the system of equations, which in effect complete the definition of the coordinate datum. The minimum number of these constraints must equal to the datum defect $d$. The solution determined by such a process is called a minimal constrained solution. It is important to realize that the introduction of arbitrary constraint equations will lead to arbitrary estimates from the solution. This is of particular importance in the analysis of geodetic networks, and in the application of networks to deformation monitoring. The conventional solution of defining the geodetic datum for the network is to delete the $\mathrm{d}$ colums of the design matrix $\mathrm{A}$ which refer to the points coordinates being kept fixed, before forming the system of normal equations. The best estimate for the least squares solution vector $x$ can be computed as follows [ 1,2 ] :

$$
\hat{\mathbf{x}}=\left(\mathbf{A}^{\mathrm{T}} \mathbf{P A}\right)^{-1} \mathbf{A}^{\mathrm{T}} \mathbf{P L}=\mathbf{N}^{-1} \mathbf{A}^{\mathrm{T}} \mathbf{P L}
$$

And the $(u-d \times u-d)$ variance - covariance matrix of the estimated coordinates can be computed using the following relation:

$$
C_{\hat{X}}=\hat{\sigma}_{o}^{2} Q_{\hat{X}}=\hat{\sigma}_{o}^{2}\left(A^{T} P A\right)^{-1}
$$

Where $Q_{\hat{X}}$ is the (u-d $\left.x u-d\right)$ weight coefficient matrix of the estimated coordinates and $\hat{\sigma}_{0}^{2}$ is the a posteriori variance factor.

\subsection{The Inner Constraint Approach}

The inner constraint approach is based on imposing some internal constraints on the average positional, rotational and scale changes throughout the network when the adjustment process is performed. This means that the centroid of the approximate coordinates and their average orientation and scale are maintained after the adjustment process. The inner constraint approach has been widely used and is often reputed to remove the problem datum definition. The general form of the expanded matrix of the normal equations, augmented by the inner constraints, can be expressed by $[2,6]$.

$$
\left(\begin{array}{ll}
N^{T} & G \\
G^{T} & 0
\end{array}\right):\left[\begin{array}{l}
\hat{x} \\
k
\end{array}\right]=\left(\begin{array}{c}
A^{T} P L \\
0
\end{array}\right)
$$


Where the $(u \times d)$ inner constraints matrix $U$ rows span tne nuin space un uic uesign matrix $A$ or the null space of the normal equations coefficient matrix, satisfying the following relations :

$$
\mathbf{G}^{\mathbf{T}} \hat{\mathbf{x}}=\mathbf{0}, \quad \mathbf{A} \mathbf{G}=\mathbf{0} \quad \text { and } \quad \mathbf{N ~ G}=\mathbf{0}
$$

The regular inverse of the expanded matrix in equation (7), which is given by

$$
\left(\begin{array}{ll}
N & G \\
G^{T} & 0
\end{array}\right)^{-1}=\left(\begin{array}{cc}
Q^{+} & G\left(G^{T} G\right)^{-1} \\
\left(G^{T} G^{-1} G^{T}\right. & 0
\end{array}\right)
$$

Leads to the weight coefficient matrix of the estimated coordinates as pseudo inverse of the normal equations coefficient matrix [ 3 ]

$$
Q_{x}^{+}=\left(N+G G^{T}\right)^{-1}-G\left(G^{T} G^{T} G^{-1}\right)^{T} G^{T}
$$

Which has the properties of minimum trace

$$
\text { Trace }\left(Q_{x}^{+}\right)=\operatorname{minimum} \quad \text { and } \quad Q_{x}^{+} G=0
$$

The least squares solution of the parameters $x$ subject to the inner constraints has the important characteristic of having minimum norm for the unknown coordinates parameters [3]

With

$$
\hat{\mathbf{x}}=\left(\mathbf{N}+\mathbf{G} \mathbf{G}^{\mathrm{T}}\right)^{-1} \mathbf{A}^{\mathrm{T}} \mathbf{P L}
$$

$$
\hat{\mathbf{x}} \hat{\mathbf{x}}=\text { minimum or } \quad \hat{\mathbf{x}}^{\mathrm{T}} \mathbf{P} \hat{\mathbf{x}}=\text { minimum }
$$

\section{PARTIAL TRACE MINIMIZATION APPROACH}

In some practical cases, such as the deformation monitoring networks, it is desirable that only some of the points in the geodetic network are contribute to the definition of the datum. In this case both the trace of the covariance matrix and the norm of the solution vector of that subset of the netpoints should be minimized. This can be achieved by using of the following $(u, d)$ matrix $B$

$$
\mathbf{B}=\mathbf{E} \mathbf{G}
$$

Where $E$ is a $(u \times u)$ quadratic unit matrix except for zeros on the diagonal corresponding to coordinates not required to contribute to the datum. Then, the general form of the expanded matrix of the normal equations can be expressed as follows $[5,7]$ : 


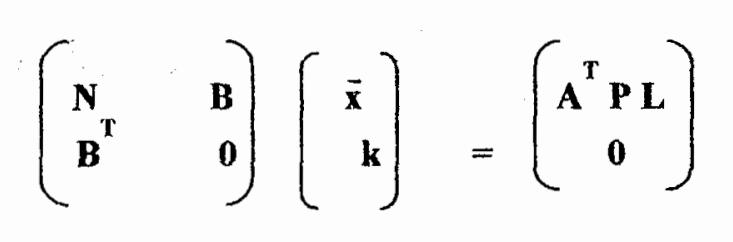

Where B is the ( uxu ) modified inner constraints matrix. The general expression for the regular inverse is obtained as follows:

$$
\left(\begin{array}{ll}
N & B \\
B^{T} & 0
\end{array}\right)^{-1}=\left(\begin{array}{cc}
\bar{Q}_{X} & G\left(B^{T} G\right) \\
\left(G^{T} B\right)^{-1} G^{T} & 0
\end{array}\right)^{-1}
$$

Where $Q_{x}$ is the ( $\left.u \times u\right)$ weight coefficient matrix of the estimated coordinates as reflexive generalised inverse of the normal equations coefficient matrix

$$
\bar{Q}_{x}=\left(N+B B^{T}\right)^{-1}-G\left(G^{T} B B^{T} G\right)^{-1} G^{T}
$$

Which has the minimum partial trace. The least squares solution of the parameters subject to the modiefied inner constraints can be computed as

$$
\bar{x}=\left(N+B B^{T}\right)^{-1} A^{T} P L
$$

Which has also the minimum partial norm. Also, the conditions in equation ( 8 ) can also be rewritten as follows :

$$
\mathbf{B}^{\mathrm{T}} \overline{\mathrm{x}}=\mathbf{0}, \quad \mathrm{NG}=\mathbf{0} \text { and } \overline{\mathrm{Q}}_{\mathrm{x}} \mathrm{B}=\mathbf{0}
$$

By denoting the datum - points, which contribute to the datum definition by the suffix $\mathrm{D}$, and they can be arranged in the upper place of the unknown parameter vector. The remaining netpoints denoted by the suffix $(N)$ can also be arranged in the lower place of the following vectors and matrices as follows:

$\overline{\mathbf{x}}=\left[\begin{array}{c}\overline{\mathbf{x}}_{\mathrm{D}} \\ \overline{\mathbf{x}}_{\mathrm{N}}\end{array}\right], G=\left(\begin{array}{c}\mathbf{G}_{\mathrm{D}} \\ \mathbf{G}_{\mathrm{N}}\end{array}\right], \mathrm{B}=\left[\begin{array}{c}\mathrm{G}_{\mathrm{D}} \\ \mathbf{0}\end{array}\right), \mathrm{H}=\left(\begin{array}{ll}\mathrm{I}_{\mathrm{DD}} & \mathbf{0}_{\mathrm{DN}} \\ \mathbf{0}_{\mathrm{ND}} & \mathbf{0}_{\mathrm{NN}}\end{array}\right)$

The regular inverse of the expanded normal malrix in equation ( 16) can be rewritten as follows:

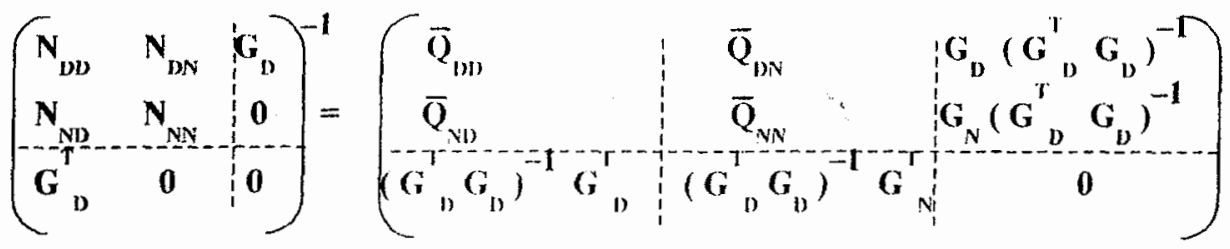

In which 


$$
\vec{N}_{\mathrm{DD}} \mathbf{G}_{\mathrm{D}}=\mathbf{0}, \overrightarrow{\mathrm{Q}}_{\mathrm{DD}} \mathrm{G}_{\mathrm{D}}=\mathbf{0} \text { and } \mathrm{G}_{\mathrm{D}}^{1} \overline{\mathrm{x}}_{\mathrm{D}}=\mathbf{0}
$$

And

$$
\begin{aligned}
& \overline{\mathbf{Q}}_{\mathrm{DD}}=\mathrm{N}^{+} \mathrm{DD} \\
& \overline{\mathbf{Q}}_{\mathrm{DN}}=-\overline{\mathbf{Q}}_{\mathrm{DD}} \mathbf{N}_{\mathrm{DN}} \mathrm{N}_{\mathrm{NN}}^{-1} \\
& \overline{\mathbf{Q}}_{\mathrm{ND}}=-\mathbf{N}_{\mathrm{NN}} \mathbf{N}_{\mathrm{ND}} \overline{\mathbf{Q}}_{\mathrm{DD}} \\
& \overline{\mathbf{Q}}_{\mathrm{NN}}=\mathrm{N}_{\mathrm{NN}}^{-1}+\mathrm{N}_{\mathrm{NN}}^{-1} \mathbf{N}_{\mathrm{ND}} \overline{\mathbf{Q}}_{\mathrm{DD}} \mathbf{N}_{\mathrm{DN}} \mathbf{N}_{\mathrm{NN}}^{-1}
\end{aligned}
$$

If only $d$ parameters are used to define the coordinate datum, then

$$
\bar{Q}_{X}=\left(\begin{array}{ll}
0_{D D} & 0_{D N} \\
0_{N D} & N_{N}^{-1}
\end{array}\right)
$$

In which

$\vec{Q}_{\mathrm{DD}}=0, \overline{\mathrm{Q}}_{\mathrm{DN}}=0, \overline{\mathrm{Q}}_{\mathrm{ND}}=0$ and $\overline{\mathrm{Q}}_{\mathrm{NN}}=\mathrm{N}_{\mathrm{NN}}^{-1}$

\section{S-TRANSFORMATION AND ITS APPLICATION:}

Datum changes may be obtained by S-transformations in order to select the proper coordinate datum. S-transformations were first described in published form by baarda (1973). The estimated point coordinates and their covariance matrix can be transformed from one computational base to another without repeating the adjustment process via an S-transformation. The transformation from an arbitrary datum (i) to a certain datum $(j)$ can be achieved for the datum dependent coordinates and their covariance matrix with the following formulas $[2,3]$ :

In which

$$
\mathbf{x}_{\mathbf{j}}=S_{\mathbf{j}} \mathbf{x}_{\mathbf{i}} \quad \text { and } \quad\left(C_{\mathbf{x}}\right)_{\mathbf{j}}=S_{j} \quad\left(C_{\mathbf{x}}\right)_{\mathbf{i}} \quad S_{j}{ }^{\mathrm{T}}
$$

$$
S_{\mathrm{j}}=S_{m}=I-G\left(G^{T} G\right)^{-1} G^{T}
$$

Where $S_{m}$ is the $S$ - transformation matrix which derived from the pseudo inverse using the inner constraints. This Transformation matrix $S_{n 1}$ are useful when transforming a regular covariance matrix of coordinates into a singular one with the required rank deficiency or vice verse $[3,8]$. In some cases it is required that only some of the netpoints should be contributed to the definition of the datum and that the trace of the covariance matrix of that subset of net points be minimised. This can be achieved by the use of the matrix $\mathrm{E}$ inserted into equation (27) as follows:

$$
S_{p}=I-G\left(G^{T} E G\right)^{-1} G^{T} E
$$


According to equation (21), the transformation matrix $S_{p}$ can be in general case partitioned in submatrices of datum netpoints ( with suffix $D$ ) and the remaining netpoints ( with suffix $N$ ). Then

$$
S_{p}=\left(\begin{array}{ccc:c}
I_{D D}-G_{D}\left(G_{D}^{T} G_{D}\right)^{-1} & G^{T} & 0_{D N} \\
\hdashline-G_{N}\left(G^{T} G_{D}\right)^{-1} & G^{T} & I_{N N}
\end{array}\right]
$$

With symmetric Transformation matrix

$$
S_{D D}=I_{D D}-G_{D}\left(G_{D}^{T} G_{D}\right)^{-1} G_{D}^{T}=I_{D D}-R_{D D}
$$

And

$$
\overline{\mathrm{Q}}_{\mathrm{DD}}=\mathrm{S}_{\mathrm{DD}} \overline{\mathrm{Q}}_{\mathrm{DD}} \mathrm{S}_{\mathrm{DI}} \quad \text { and } \quad \overline{\mathrm{x}}_{\mathrm{D}}=\mathrm{S}_{\mathrm{DD}} \quad \mathrm{x}_{\mathrm{D}}
$$

Both equations ( 28 ) and ( 29 ) can be considered as the general form of the transformation matrix. For a two dimensional geodetic monitoring network with $\mathrm{m}$ points, the transformation matrix $S_{p}$ in equation (29) can be expressed in more detail as follows:

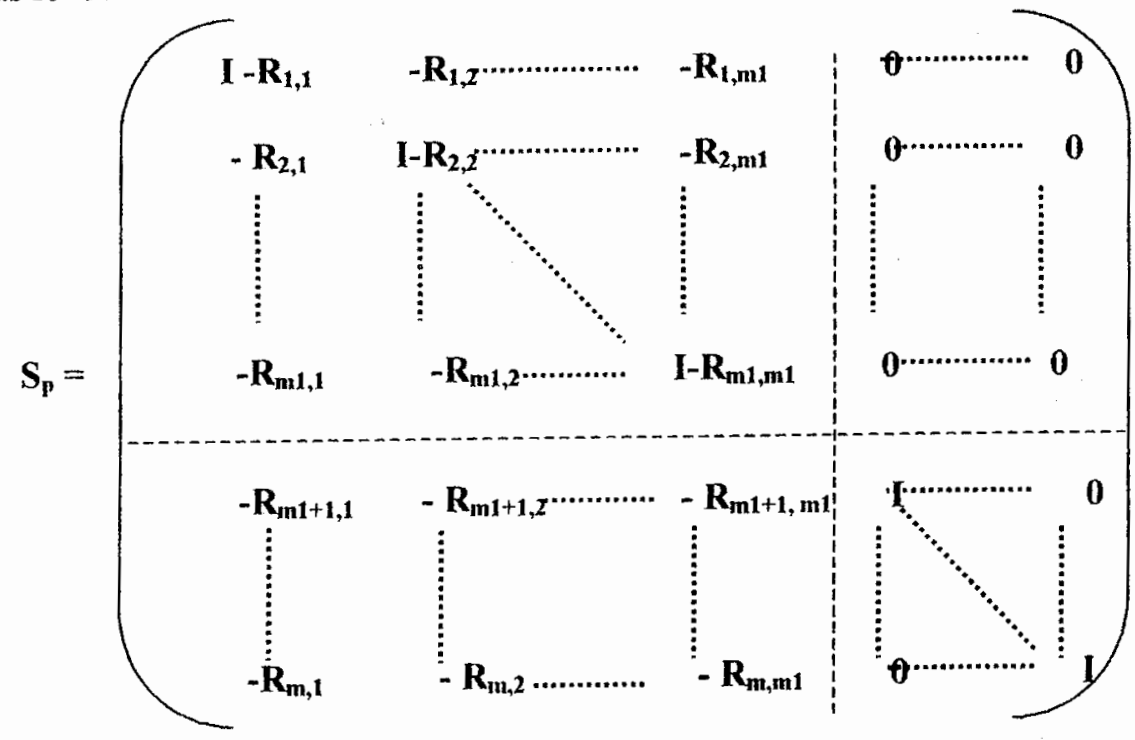

In which

$$
R_{i, k}=\left(\begin{array}{cc}
G_{1}\left(G_{k}{ }_{k} G_{k}\right)^{-1} & G_{k}^{T}, \text { for } k=1 \ldots m_{1} \\
0 & , \text { for } m_{1}<k<=m
\end{array}\right)
$$


$S_{i, k}=\left(\begin{array}{cccc}I-R_{i, k} & , & \text { for } & k=i \\ -R_{i, k} & , & \text { for } & k=i\end{array}\right)$

Where $m_{1}$ is the number of datum - points in the network.

If only $d$ parameter are used to define the datum, then. The matrix $G_{D}$ is quadratic matrix with the dimenision $d$, and the inverse $\left(G_{D}^{T} G_{D}\right)^{-1}$ is regular. The transformation matrix in equation (29) can be written in this case as follows :

$S_{d}=\left(\begin{array}{c:c}0 & 0 \\ (d, d) & (d, m-d) \\ \hdashline-G_{N} G^{-1} & I \\ (m-d, d) & (m-d, m-d)\end{array}\right)$

In which

$$
S_{\mathrm{Db}}=0, \mathrm{~S}_{\mathrm{NN}}=\mathrm{I} \text { and } \mathrm{S}_{\mathrm{ND}}=-\mathrm{G}_{\mathrm{N}} \mathbf{G}_{\mathrm{D}}^{-1}
$$

And

$$
\mathrm{x}_{\mathrm{DD}}=\mathbf{0}, \mathbf{Q}_{\mathrm{DD}}=0 \text { and } \mathrm{Q}_{\mathrm{NN}}=\mathrm{N}^{-1}{ }_{\mathrm{NN}}
$$

The following relations represent the structure of the transformations matrices for different datum defects which their elements can preferable be computed using the approximate netpoints coordinates relative to the centroid of all the netpoints. For each number of datum defects, the appropriate matrices can be setup as subsets of the inner constraints matrix $G$, so that datum transformations may be performed for all types of horizontal geodetic monitoring networks [ 5 ].

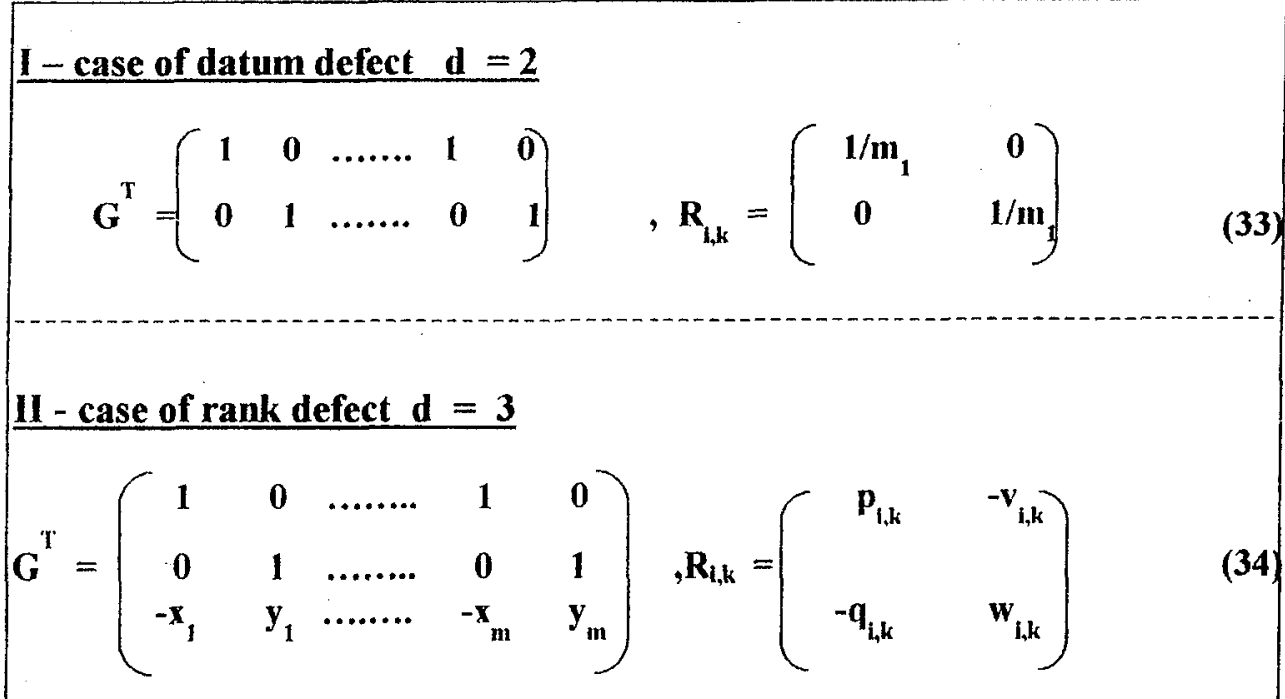




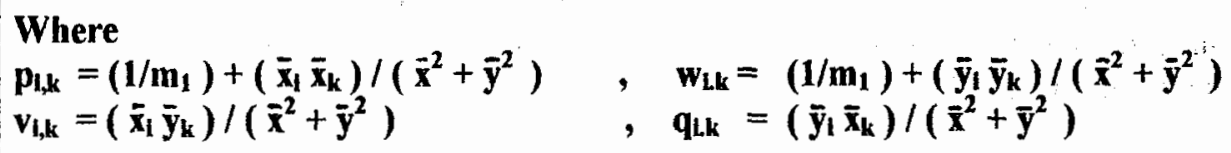

In which

$$
\begin{array}{ll}
\bar{y}_{1}=y_{1}-\left(1 / m_{1}\right) \Sigma y_{k} & k=1 \ldots m_{1} \\
\bar{x}_{1}=x_{1}-\left(1 / m_{1}\right) \Sigma x_{k} & k=1 \ldots m_{1}
\end{array}
$$

III - case of datum defect $d=4$

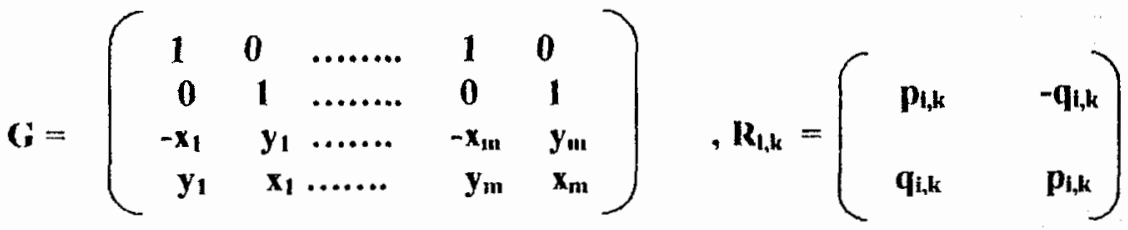

In which

$P_{1, k}=\left(1 / m_{1}\right)+\left(\bar{x}_{1} \bar{x}_{k}+\bar{y}_{1} \bar{y}_{k}\right) /\left(\bar{x}^{2}+\bar{y}^{2}\right)$

$q_{1 . k}=\left(\bar{x}_{i} \bar{y}_{k}-\bar{y}_{i} \bar{x}_{k}\right) /\left(\bar{x}^{2}+\bar{y}^{2}\right)$

$$
\begin{array}{ll}
\bar{y}_{1}=y_{1}-\left(1 / m_{1}\right) \Sigma y_{k} & k=1 \ldots m_{1} \\
\bar{x}_{i}=x_{i}-\left(1 / m_{1}\right) \Sigma x_{k} & k=1 \ldots m_{1}
\end{array}
$$

\section{NUMERICAL EXAMPLES}

\subsection{Simulated Geodetic Network}

The schematic two - dimensional trilateration network is used to demonstrate the above derived results. This local network is composed of four new points $\mathbf{P} 1, \ldots, \mathbf{P} 4$ with unknown coordinates as shown in fig. (1). The approximate coordinates of the new net points are listed in table (2) with respect to the selected local horizontal coordinate system.

Table 1: The approximate coordinates of the

\begin{tabular}{|c|c|c|}
\hline \multicolumn{3}{|c|}{ netpoints } \\
\hline points & $\mathbf{X}(\mathbf{m})$ & $\mathbf{Y}(\mathbf{m})$ \\
\hline $\mathbf{P}_{1}$ & 0 & 0 \\
$\mathbf{P}_{2}$ & 100 & 0 \\
$\mathbf{P}_{3}$ & 100 & 100 \\
$\mathbf{P}_{4}$ & 0 & 100 \\
\hline
\end{tabular}

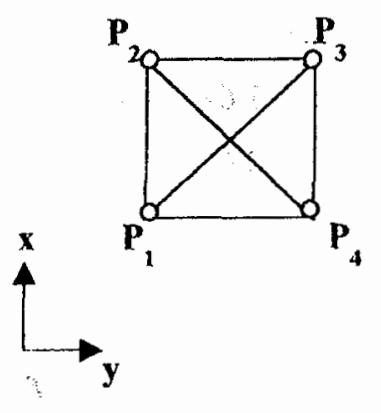

Fig. I : A schematic geodetic network 
The simulated network was adjusted as a free trilateration network using the inner constraints approach. In this study, the inner constraints matrix $G$ was given in the following three cases as follows :

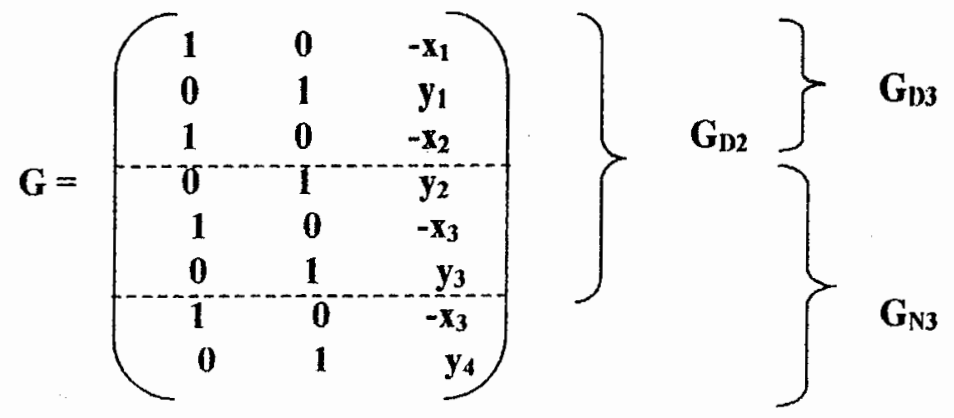

\subsection{Real Geodetic Network}

A two - dimensional hybrid network comprising six points is established in $\mathrm{El}$ Mansoura city ( Sandoub zone ). The configuration of the network points is shown in Fig. 2. All directions and distances of the network legs were observed using SOKKIA ( SET 5 ) Total station. The standard errors of the observed directions was three second whereas the standard deviation of the measured distances is $\pm(5 \mathrm{~mm}+5 \mathrm{ppm})$. The approximate coordinates of the netpoints are listed in table (2) with respect to the selected local horizontal coordinate system.

Table2. The approximate coordinates of the net points

\begin{tabular}{|c|c|c|}
\hline Points & $\mathrm{X}_{(\mathrm{m})}$ & $\mathrm{Y}_{(\mathrm{m})}^{\mathrm{O}}$ \\
\hline $\mathrm{P}_{1}$ & 2708.294 & 2000.235 \\
$\mathrm{P}_{2}$ & 2002.848 & 1999.845 \\
$\mathrm{P}_{3}$ & 1920.192 & 3017.159 \\
$\mathrm{P}_{4}$ & 2356.732 & 4174.899 \\
$\mathrm{P}_{5}$ & 3051.645 & 4003.819 \\
$\mathrm{P}_{6}$ & 2750.647 & 2971.591 \\
\hline
\end{tabular}

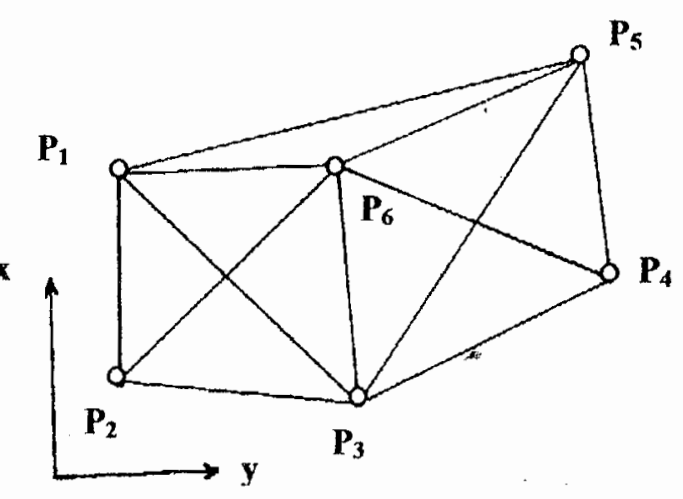

Fig. 2 : A real geodetic network subjected to $S$ - transformation 


\section{RESULTS AND DISCUSSIONS}

The covariance matrix of the estimated coordinates $C_{m}$, which has the minimum trace, was computed according the equation (10) as follows:

$$
C_{m}=\left(\begin{array}{cccccccc}
0.281 & 0.031 & -0.094 & 0.094 & -0.031 & -0.031 & -0.156 & -0.094 \\
& 0.281 & -0.094 & -0.156 & -0.031 & -0.031 & 0.094 & -0.094 \\
& & 0.281 & -0.031 & -0.156 & 0.094 & -0.031 & 0.031 \\
\text { Symm. } & & & 0.281 & -0.094 & -0.094 & 0.031 & -0.031 \\
& & & & 0.281 & 0.031 & -0.094 & 0.094 \\
& & & & & 0.281 & -0.094 & -0.156 \\
& & & & & & 0.281 & -0.031 \\
& & & & & & & 0.281
\end{array}\right)
$$

\section{1-Case (A):}

If the coordinates of all four netpoints were contribute to the datum definition. This means that $\left(\mathrm{m}=\mathrm{m}_{1}=4, \mathrm{u}=\mathrm{u}_{1}=8\right.$ and $\left.\mathrm{B}_{1}=\mathrm{G}\right)$.

The transformation matrix $S_{m}$ was computed using the equation (27) as follows :

$S_{m}=\left(\begin{array}{cccccccc}0.6250 & 0.125 & -0.125 & 0.125 & -0.125 & -0.125 & -0.375 & -0.125 \\ & 0.625 & -0.125 & -0.375 & -0.125 & -0.125 & 0.125 & -0.125 \\ & & 0.625 & -0.125 & -0.375 & 0.125 & -0.125 & 0.125 \\ \text { Symm. } & & & 0.625 & -0.125 & -0.125 & 0.125 & -0.125 \\ & & & & 0.625 & 0.125 & -0.125 & 0.125 \\ & & & & & 0.625 & -0.125 & -0.375 \\ & & & & & & 0.625 & -0.125 \\ & & & & & & 0.625\end{array}\right)$

In which $\quad S_{1}=S_{n} \quad$ with the following properties

And

$$
S_{1} G=0, S_{1}=S_{1}^{T_{1}} \text { and } S_{1} . S_{1}=S_{1} \quad \text { (i.e } S_{1} \text { is idempotent) }
$$

$$
\Sigma S_{1, k}=0 \quad \text { for } i=1 \ldots u, k=1 \quad \ldots \quad u
$$

The corresponding covariance matrix of the estimated coordinates $C_{1}$, which was computed from the following relation

$$
C_{1}=S_{1} \quad C_{m} S_{1}
$$

gave identical numerical values to those obtained by using inner constraints approach $\mathrm{C}_{\mathrm{m}}$ (i.e $\mathrm{C}_{1}=\mathrm{C}_{\mathrm{m}}$ ) and

$$
\operatorname{Trace}\left(C_{1}\right)=\operatorname{Trace}\left(C_{m 1}\right)=2.250
$$




\section{II-Case (B):}

If three netpoints were contribute to the datum definition. This means that the three netpoints $\left(P_{1}, P_{2}\right.$ and $\left.P_{3}\right)$ were datum points $\left(m_{1}=3, u_{1}=6, u=8\right)$

and $\quad B=\left(\begin{array}{c}G_{D 2} \\ 0\end{array}\right)$

The computed transformation matrix $\mathrm{S}_{2}$ were

$$
S_{2}=\left(\begin{array}{cccccc:c:c}
0.333 & 0.167 & -0.167 & 0.167 & -0.167 & -0.333 & 0.000 & 0.000 \\
& 0.583 & -0.083 & -0.417 & -0.083 & -0.167 & 0.000 & 0.000 \\
& & 0.583 & -0.083 & -0.417 & 0.167 & 0.000 & 0.000 \\
\text { Symm. } & & & 0.583 & -0.083 & -0.167 & 0.000 & 0.000 \\
\hdashline-0.667 & 0.167 & -0.167 & 0.167 & -0.167 & -0.333 & 1.000 & 0.000 \\
-0.333 & -0.167 & 0.167 & -0.167 & 0.167 & -0.667 & 0.000 & 1.000
\end{array}\right)
$$

In which

$$
S_{D D}=S_{D D}^{T} \quad, \quad S_{D N}=0 \text { and } \quad S_{N N}=1
$$

With the following property

$$
\Sigma S_{1, k}=0 \quad k=1 \ldots . . u \quad, \quad i=1 \ldots \ldots u_{1}
$$

And the corresponding covariance matrix $C_{2}$ in which the top left - hand $(6 \times 6)$ sub - matrix has minimum trace was computed as follows :

$$
C_{2}=S_{2} \quad C_{m} \quad S_{2}^{T}
$$

$C_{2}=C_{\mathrm{P}}=\left(\begin{array}{cccccc:cc}0.153 & 0.056 & -0.097 & 0.097 & -0.056 & -0.153 & 0.028 & -0.028 \\ & 0.236 & -0.069 & -0.181 & 0.014 & -0.056 & 0.056 & -0.056 \\ & & 0.278 & -0.028 & -0.181 & 0.097 & 0.028 & -0.028 \\ \text { Symm. } & & & 0.278 & -0.089 & -0.097 & -0.028 & 0.028 \\ & & & & 0.236 & 0.056 & -0.056 & 0.056 \\ \hdashline 0.028 & 0.056 & 0.028 & -0.028 & -0.056 & -0.028 & 0.778 & 0.222 \\ 0.028 & -0.056 & -0.028 & 0.028 & 0.056 & 0.028 & 0.222 & 0.778\end{array}\right)$

In which

$$
C_{D N}=C_{N D}^{\mathrm{r}} \quad \text { and } \quad \operatorname{Trace}\left(C_{2}\right)=1.334+1.556=2.89
$$




\section{III-Case (C):}

- If only three netpoints coordinates were contribute to the datum definition. This means that, the netpoints coordinates $\left(\mathrm{y}_{1}, \mathrm{x}_{1}\right.$ and $\left.\mathrm{y}_{2}\right)$ were datum coordinates $\left(u_{1}=d=3, m_{1}=3 / 2\right)$

And $\quad \mathbf{B}_{3}=\left(\begin{array}{c}\mathbf{G}_{\mathrm{D} 3} \\ 0\end{array}\right)$

The transformation matrix

$$
\mathrm{S}_{3}=\left(\begin{array}{ccc:ccccc}
0.000 & 0.000 & 0.000 & 0.000 & 0.000 & 0.000 & 0.000 & 0.000 \\
\text { Symm. } & 0.000 & 0.000 & 0.000 & 0.000 & 0.000 & 0.000 & 0.000 \\
\hdashline 0.000 & -1.000 & 0.000 & 1.000 & 0.000 & 0.000 & 0.000 & 0.000 \\
0.000 & 0.000 & -1.000 & & 1.000 & 0.000 & 0.000 & 0.000 \\
-1.000 & -1.000 & 1.000 & & & 1.000 & 0.000 & 0.000 \\
-1.000 & 0.000 & 0.000 & \text { Symm. } & & 1.000 & 0.000 \\
-1.000 & -1.000 & 1.000 & & & & & 1.000
\end{array}\right)
$$

And the corresponding covariance matrix $\mathrm{C}_{3}$ was computed as follows :

$$
\begin{aligned}
& C_{3}=S_{3} \quad C_{m} \quad S_{3}^{T_{3}} \\
& \mathrm{C}_{3}=\left(\begin{array}{ccc:ccccc}
0.000 & 0.000 & 0.000 & 0.000 & 0.000 & 0.000 & 0.000 & 0.000 \\
& 0.000 & 0.000 & 0.000 & 0.000 & 0.000 & 0.000 & 0.000 \\
& & 0.000 & 0.000 & 0.000 & 0.000 & 0.000 & 0.000 \\
& & & 0.875 & -0.125 & 0.375 & -0.125 & 0.500 \\
\text { Symm. } & & & & 0.875 & -0.625 & -0.125 & -0.500 \\
& & & & & 1.875 & 0.375 & 1.500 \\
& & & & & & 0.875 & 0.500 \\
& & & & & & & 2.000
\end{array}\right)
\end{aligned}
$$

In which

$$
\operatorname{Trace}\left(\mathrm{C}_{3}\right)=6.500
$$

Based on the previous results, the following relations can be deduced:

$$
\begin{aligned}
& C_{m}=S_{m} C_{p} S_{m}=S_{m} C_{d} S_{m}=S_{m} C_{m} S_{m} \\
& C_{p}=S_{p} C_{d} S_{p}^{T}=S_{p} C_{m} S_{p}^{T}=S_{p} C_{p} S_{p}^{T} \\
& C_{d}=S_{d} C_{m} S_{d}^{T}=S_{d} C_{p} S_{d}^{T}=S_{d} C_{d} S_{d}^{T}
\end{aligned}
$$


Table 3: Effect of the number and geometry of datum - points on the positional accuracy of the real network.

\begin{tabular}{|c|c|c|c|c|c|c|c|c|}
\hline \multicolumn{3}{|c|}{ Total inner constraints } & \multicolumn{4}{|c|}{ Parlial imer constraints } & \multicolumn{2}{|c|}{ Minimal consiraints } \\
\hline & \multirow{2}{*}{$\begin{array}{l}\stackrel{.}{\Xi} \\
0 \\
\dot{0} \\
Z \\
Z\end{array}$} & $\begin{array}{c}\text { Variant } \\
\text { (1) }\end{array}$ & $\begin{array}{c}\text { Variant } \\
\text { (2) }\end{array}$ & $\begin{array}{c}\text { Variant } \\
\text { (3) }\end{array}$ & $\begin{array}{c}\text { Variant } \\
\text { (4) }\end{array}$ & $\begin{array}{c}\text { Variant } \\
(5)\end{array}$ & $\begin{array}{c}\text { Variant } \\
(6)\end{array}$ & $\begin{array}{c}\text { Variant } \\
(7)\end{array}$ \\
\hline & & $\begin{array}{l}\text { Six datum } \\
\text { points }\end{array}$ & $\begin{array}{c}\text { Five datum } \\
\text { points } \\
\left(\mathrm{P}_{1}, \mathrm{P}_{2}, \mathrm{P}_{3} \mathrm{P}_{4}, \mathrm{P}_{\mathrm{s}}\right)\end{array}$ & $\begin{array}{c}\text { Four datum } \\
\text { points } \\
\left(\mathrm{P}_{1}, \mathrm{P}_{2}, \mathrm{P}_{3} \mathrm{P}_{4}\right)\end{array}$ & $\begin{array}{c}\text { Three } \\
\text { datum } \\
\text { points } \\
\left(\mathrm{P}_{1}, \mathrm{P}_{2}, \mathrm{P}_{3}\right)\end{array}$ & $\begin{array}{c}\text { Two datum } \\
\text { points } \\
\left(P_{1}, P_{2}\right)\end{array}$ & $\begin{array}{l}\text { Three datum } \\
\text { coordinates } \\
\left(y_{1}, y_{1}, y_{2}\right)\end{array}$ & $\begin{array}{l}\text { Three datum } \\
\text { coordinates } \\
\left(x_{5} ; y_{6}, x_{6}\right)\end{array}$ \\
\hline \multirow{6}{*}{$\begin{array}{c}\sigma_{\mathrm{p}} \\
(\mathrm{cm})\end{array}$} & $P_{1}$ & 0.41 & 0.39 & 0.38 & 0.33 & 0.24 & 0.00 & 1.19 \\
\hline & $P_{2}$ & 0.47 & 0.45 & 0.43 & 0.37 & 0.24 & 0.47 & 1.36 \\
\hline & $\mathbf{P}_{3}$ & 0.42 & 0.44 & 0.42 & 0.29 & 0.97 & 1.00 & 0.82 \\
\hline & $\mathbf{P}_{4}$ & 0.46 & 0.44 & 0.39 & 1.01 & 1.81 & 1.83 & 0.72 \\
\hline & $P_{s}$ & 0.40 & 0.38 & 0.58 & 0.96 & 1.70 & 1.72 & 0.39 \\
\hline & $\mathrm{P}_{6}$ & 0.49 & 0.59 & 0.59 & 0.58 & 0.90 & 0.94 & 0.00 \\
\hline \multirow{6}{*}{$\begin{array}{c}\mathrm{A} \\
(\mathrm{cm})\end{array}$} & $P_{1}$ & 0.29 & 0.29 & 0.29 & 0.26 & 0.24 & 0.00 & 1.13 \\
\hline & $\mathbf{P}_{2}$ & 0.36 & 0.35 & 0.34 & 0.28 & 0.24 & 0.47 & 1.30 \\
\hline & $\mathrm{P}_{3}$ & 0.34 & 0.38 & 0.36 & 0.25 & 0.90 & 0.93 & 0.72 \\
\hline & $\mathrm{P}_{4}$ & 0.35 & 0.35 & 0.33 & 0.91 & 1.74 & 1.77 & 0.59 \\
\hline & $P_{5}$ & 0.29 & 0.28 & 0.57 & 0.89 & 1.66 & 1.68 & 0.38 \\
\hline & $\mathrm{P}_{6}$ & 0.43 & 0.52 & 0.51 & 0.47 & 0.84 & 0.87 & 0.00 \\
\hline \multirow{6}{*}{$\begin{array}{c}\text { B } \\
(\mathrm{cm})\end{array}$} & $P_{1}$ & 0.28 & 0.26 & 0.25 & 0.20 & 0.00 & 0.00 & 0.38 \\
\hline & $P_{2}$ & 0.30 & 0.28 & 0.26 & 0.25 & 0.00 & 0.00 & 0.42 \\
\hline & $\mathrm{P}_{3}$ & 0.23 & 0.22 & 0.22 & 0.14 & 0.37 & 0.37 & 0.38 \\
\hline & $\mathrm{P}_{4}$ & 0.29 & 0.27 & 0.20 & 0.44 & 0.47 & 0.47 & 0.41 \\
\hline & $P_{5}$ & 0.27 & 0.26 & 0.34 & 0.34 & 0.37 & 0.38 & 0.00 \\
\hline & $P_{6}$ & 0.23 & 0.28 & 0.29 & 0.33 & 0.32 & 0.34 & 0.00 \\
\hline \multicolumn{2}{|c|}{ Trace $\left(C_{x}\right)$} & 1.164 & 1.222 & 1.345 & 2.606 & 8.022 & 8.433 & 4.610 \\
\hline \multicolumn{2}{|c|}{$\left\|x^{1} \times\right\|$} & 1.455 & 1.488 & 1.691 & 4.100 & 35.566 & 34.156 & 2.303 \\
\hline
\end{tabular}

Table 3. shows the effect of number and geometry of the datum-points on the points position accuracy for real geodetic network, while table (4) shows the transformed corrections to the approximate coordinates for the seven network variants. From these results, it can be found that:

1- As the number of the datum-points within the network decrease, the numerical values of the positional error $\sigma p_{i}$ as well as the parameters of error ellipse $\left(A_{i}, B_{i}\right)$ increase.

2- As the number of the datum-points within the network decrease, the numerical values of the trace of the covariance matrix of the estimated coordinates and the norm of the solution vector increase.

3. The datum-points receive the smallest numerical values of the correction than the remaining points within the network. 
Table 4: The transformed corrections to the approximate coordinates $(\mathrm{cm})$.

\begin{tabular}{|c|c|c|c|c|c|c|c|c|}
\hline \multicolumn{3}{|c|}{$\begin{array}{l}\text { Total inner } \\
\text { constraints }\end{array}$} & \multicolumn{4}{|c|}{ Partial inner constraints } & \multicolumn{2}{|c|}{ Minimal constraints } \\
\hline & \multirow{2}{*}{ 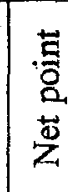 } & $\begin{array}{c}\text { Variant } \\
(1)\end{array}$ & $\begin{array}{l}\text { Variant } \\
\text { (2) }\end{array}$ & $\begin{array}{c}\text { Variant } \\
\text { (3) }\end{array}$ & $\begin{array}{l}\text { Variant } \\
\text { (4) }\end{array}$ & $\begin{array}{l}\text { Variant } \\
\text { (5) }\end{array}$ & $\begin{array}{c}\text { Variant } \\
(6)\end{array}$ & $\begin{array}{c}\text { Variant } \\
(7)\end{array}$ \\
\hline & & $\begin{array}{c}\text { Six datum } \\
\text { points }\end{array}$ & $\begin{array}{l}\text { Five datum } \\
\text { points } \\
\left(P_{1}, P_{2}, P_{3} P_{4}, P_{4}\right)\end{array}$ & $\begin{array}{l}\text { Four datum } \\
\text { points } \\
\left(P_{1}, l_{2}, l_{3} l_{4}\right)\end{array}$ & $\begin{array}{c}\text { Thiree } \\
\text { datum } \\
\text { points } \\
\left(\mathrm{P}_{1} \mathrm{P}_{2} \mathrm{P}_{3}\right)\end{array}$ & $\begin{array}{l}\text { Two } \\
\text { datum } \\
\text { points } \\
\left(\mathrm{P}_{1} \mathrm{P}_{2}\right)\end{array}$ & $\begin{array}{l}\text { Three datum } \\
\text { coordinates } \\
\left(y_{1}, y_{1}, y_{2}\right)\end{array}$ & $\begin{array}{l}\text { Three datum } \\
\text { coordinates } \\
\left(x_{5}, y_{6}, x_{6}\right)\end{array}$ \\
\hline \multirow{4}{*}{$\begin{array}{l}\mathrm{d}_{\mathrm{x}} \\
\mathrm{d}_{\mathrm{y}} \\
\mathrm{d}_{\mathrm{x}} \\
\mathrm{d}_{\mathrm{y}}\end{array}$} & $\mathbf{P}_{1}$ & -0.20 & -0.12 & -0.10 & -0.16 & 0.07 & 0.00 & -0.65 \\
\hline & & 0.83 & 0.83 & 0.82 & 0.59 & 0.00 & 0.00 & 0.81 \\
\hline & $\mathbf{P}_{2}$ & -0.33 & -0.25 & -0.23 & -0.29 & 10.07 & -0.13 & -0.78 \\
\hline & & -0.25 & -0.25 & -0.20 & -0.17 & 0.00 & 0.00 & -0.20 \\
\hline \multirow{2}{*}{$\begin{array}{l}d_{x} \\
d_{y}\end{array}$} & $\mathrm{P}_{3}$ & -0.05 & 0.03 & 0.13 & 0.44 & 1.77 & 1.71 & -0.42 \\
\hline & & -0.53 & -0.53 & -0.47 & -0.42 & -0.15 & -0.15 & -0.48 \\
\hline \multirow{2}{*}{$\begin{array}{l}d_{x} \\
d_{y}\end{array}$} & $\mathbf{P}_{4}$ & -0.08 & -0.01 & 0.02 & 0.93 & 3.51 & 3.45 & -0.35 \\
\hline & & -0.18 & -0.18 & -0.16 & -0.26 & -0.47 & -0.47 & -0.17 \\
\hline \multirow{2}{*}{$\begin{array}{l}d_{x} \\
d_{y}\end{array}$} & $P_{5}$ & 0.28 & 0.35 & 0.54 & 1.21 & 3.61 & 3.55 & 0.00 \\
\hline & & 0.13 & 0.13 & 0.10 & -0.26 & -1.23 & -1.23 & 0.08 \\
\hline \multirow{2}{*}{$\begin{array}{l}d_{x} \\
d_{y}\end{array}$} & $P_{6}$ & 0.37 & 0.45 & 0.55 & 0.84 & 2.12 & 2.06 & 0.00 \\
\hline & & 0.02 & 0.02 & 0.01 & -0.24 & -0.87 & -0.87 & 0.00 \\
\hline
\end{tabular}

\section{CONCLUSIONS AND RECOMMENDATIONS:}

From the previous discussions, the following conclusions can be drawn:

1- The $S$ - transformation is a powerful computational tool which is capable of transforming one adjustment to another without going through the procedure of every adjustment.

2- S - transformation can be used to select the proper coordinate datum for both control and monitoring geodetic networks as well as to analyse the stability of the reference points.

3- Partial trace minimization can be considered as the general adjustment approach for free geodetic networks based on the inner constraints.

4- The transformation matrix $S$ is dependent upon the following points:

a- The number and the geometry of the datum - points which contributes to the datum definition.

b- The inner constraints matrix $\mathrm{G}$ or $\mathrm{B}$

c- The number of the datum defect $d$.

5- Positional accuracy of points in monitoring networks depends heavily on the spatial distribution of its datum-definitions points.

6- The size, shape and orientation of the error ellipses associated with the adjusted netpoints are dependent upon the selection and distribution of the datum-points .

7- To counteract the weakness in orientation, the selected datum subset can be characterized by a balanced and good geometry relative to the size and shape of the whole network. 
8- The coordinate discrepancies indicate the possible movements of netpoints between the observation epochs, but only if the datum is the same at each epoch.

9- Finally, S- transformation can also be used to solve the problem of connecting a secondary control network to a primary network, or when a GPS network is to be connected to an existing terrestrial network.

\section{REFERENCES}

1- Caspary, W.F.

2-Cooper, M.A.R.

3- Cooper, $M$. and cross, P.

4- Gründig, 1. and Bahndorf

5- Illner, I

6- Pelzer, $\mathrm{H}$.

7- Schwintzer, P.

8- Van Mierlo, J.

9- Welsch, W.
"Concepts of Network and Deformation Analysis". Monograph 11, school of surveying, university of new south wales, kensington, Australia, (1988).

"Control Surveys in Civil Engineering" Collins Professional and Technical Books, London, p. 381 (1987)

"Statistical Concepts and Their Application in Photogrammetry and Surveying" Photo-grammetric Record, vol. 13, No. 77, pp. 645-678 (1991).

"Detection and Localisation of Geometrical Movements". Journal of Surveying Engineering, vol. 111, No. 2, pp. 118 - 132, (1985).

"Freie Netze und S-Transformation". Allgemeine Vermessungs - Nachrichten, Karlsruhe vol. 90 ,No. 5, pp. 157 - 170, (1983).

"Geodätische Netze In landes - und Ingenieurvermessung". II, Stuttgart, Konrad Wittwer Verlag : pp. $153-221,(1985)$.

"Zur Berechnung von Inverses mit Minimaler Teilspur", Zeitschrift für vermessungswesen vol. 107, No. 11, pp. 514 - 516, (1982).

“ Free Network Adjustment and S - Transformations". Deutsche geodätische kommission, Reihe B, Heft Nr. 252, München pp. 41 - 54, (1979).

"A Review of the Adjustment of Free Networks", Survey Review, vol. 25, No. 194 , pp. 167 - 180, (1979). 


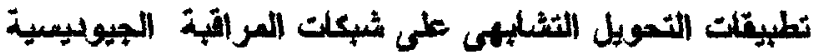

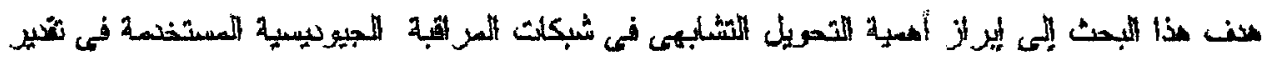

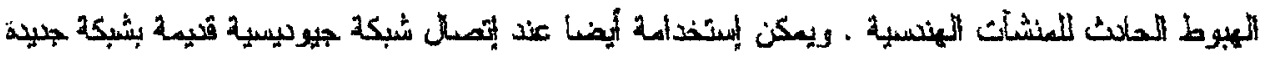

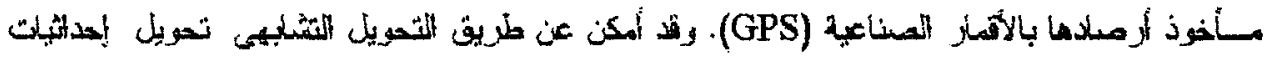

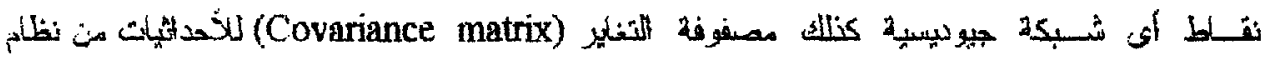

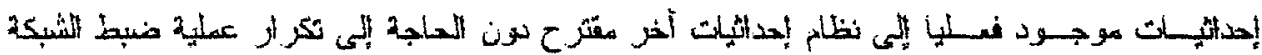

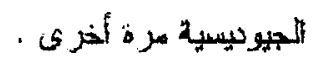

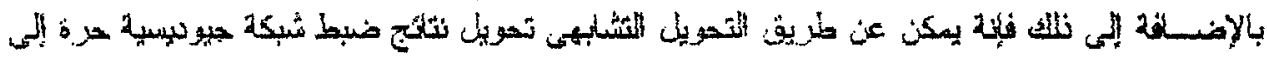

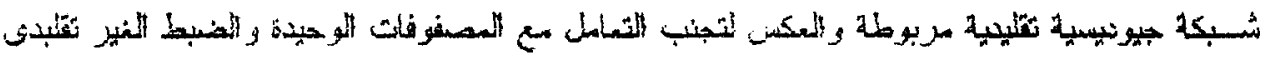

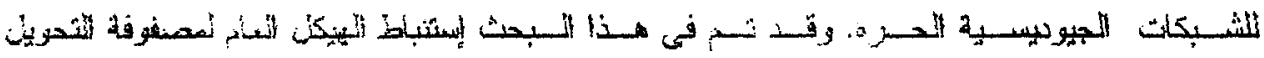

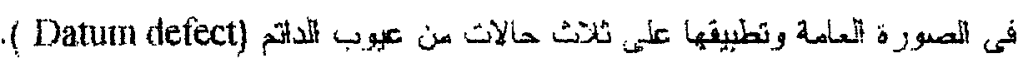

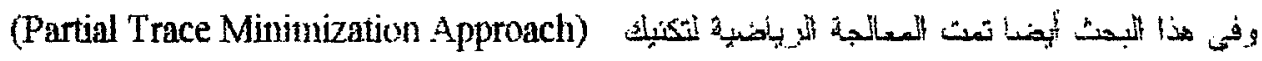

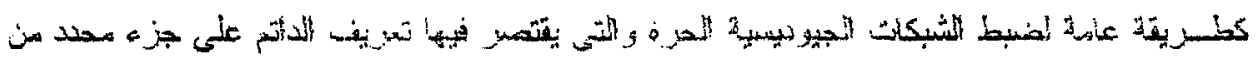

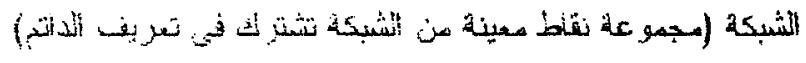

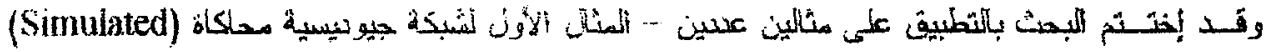

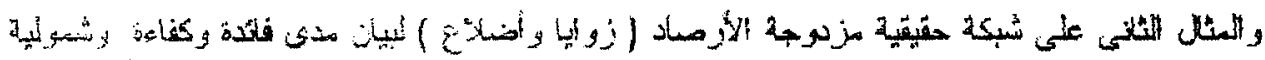

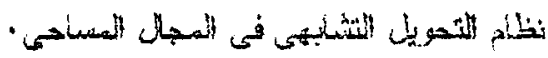

